\title{
Revealing potential lipid biomarkers in clear cell renal cell carcinoma using targeted quantitative lipidomics
}

Wen Li, ${ }^{1,2,3}$, Xiaobin Wang ${ }^{1,2,3}$, Xianbin Zhang ${ }^{1,3,4}$, Peng Gong ${ }^{1,3,4}$, Degang Ding ${ }^{5}$, Ning Wang ${ }^{5}$ and Zhifeng Wang ${ }^{5^{*}}$

\begin{abstract}
Background: The high drug resistance and metabolic reprogramming of clear cell renal cell carcinoma (ccRCC) are considered responsible for poor prognosis. In-depth research at multiple levels is urgently warranted to illustrate the lipid composition, distribution, and metabolic pathways of clinical ccRCC specimens.

Methods: In this project, a leading-edge targeted quantitative lipidomic study was conducted using 10 pairs of cancerous and adjacent normal tissues obtained from ccRCC patients. Accurate lipid quantification was performed according to a linear equation calculated using internal standards. Qualitative and quantitative analyses of lipids were performed with multiple reaction monitoring analysis based on ultra-performance liquid chromatography (UPLC) and mass spectrometry (MS). Additionally, a multivariate statistical analysis was performed using data obtained on lipids.
\end{abstract}

Results: A total of 28 lipid classes were identified. Among them, the most abundant were triacylglycerol (TG), diacylglycerol (DG), phosphatidylcholine (PC), and phosphatidylethanolamine (PE). Cholesteryl ester (CE) was the lipid exhibiting the most considerable difference between normal samples and tumor samples. Lipid content, chain length, and chain unsaturation of acylcarnitine (CAR), CE, and DG were found to be significantly increased. Based on screening for variable importance in projection scores $\geq 1$, as well as fold change limits between 0.5 and 2, 160 differentially expressed lipids were identified. CE was found to be the most significantly upregulated lipid, while TG was observed to be the most significantly downregulated lipid.

Conclusion: Based on the absolute quantitative analysis of lipids in $c C R C C$ specimens, it was observed that the content and change trends varied in different lipid classes. Upregulation of CAR, CE, and DG was observed, and analysis of changes in the distribution helped clarify the causes of lipid accumulation in CCRCC and possible carcinogenic molecular mechanisms. The results and methods described herein provide a comprehensive analysis of ccRCC lipid metabolism and lay a theoretical foundation for cancer treatment.

Keywords: Clear cell renal cell carcinoma, Lipids, Lipidomics, Lipid metabolite, Lipid biomarker, Lipid quantification, UPLC-MS/MS, Differentially expressed lipids

\footnotetext{
* Correspondence: shengyiwzf@163.com

${ }^{5}$ Department of Urology, Henan Provincial People's Hospital, Zhengzhou

University People's Hospital, Henan University People's Hospital, No. 7 Weiwu

Road, Zhengzhou City 450003, Henan Province, China

Full list of author information is available at the end of the article
}

(c) The Author(s). 2021 Open Access This article is licensed under a Creative Commons Attribution 4.0 International License, which permits use, sharing, adaptation, distribution and reproduction in any medium or format, as long as you give appropriate credit to the original author(s) and the source, provide a link to the Creative Commons licence, and indicate if changes were made. The images or other third party material in this article are included in the article's Creative Commons licence, unless indicated otherwise in a credit line to the material. If material is not included in the article's Creative Commons licence and your intended use is not permitted by statutory regulation or exceeds the permitted use, you will need to obtain permission directly from the copyright holder. To view a copy of this licence, visit http://creativecommons.org/licenses/by/4.0/ The Creative Commons Public Domain Dedication waiver (http://creativecommons.org/publicdomain/zero/1.0/) applies to the data made available in this article, unless otherwise stated in a credit line to the data. 


\section{Background}

According to cancer statistics reported in 2021, renal cell carcinoma ranks sixth among new cancer cases in men and ranks ninth among new cases in women [1]. Clear cell renal cell carcinoma (ccRCC) accounts for $70 \%$ of all renal cell carcinoma patients and is the main pathological feature of lipid accumulation [2]. Loss of the Von Hippel Lindau (VHL) gene and deletion of a part of chromosome 3p are involved in the initial steps, and vascular endothelial growth factor, PI3K, mTOR, and carbonic anhydrase IX have been defined as therapeutic targets [3]. Owing to poor prognosis attributable to drug resistance and immune escape, it is suggested that the discovery of more potential molecular mechanisms holds considerable promise $[4,5]$.

Metabolomics based on nuclear magnetic resonance (NMR), chromatography, and mass spectrometry (MS) can be considered to systematically analyze the variations under different physiological conditions using a combination of genomics and proteomics [6]. As an independent branch of metabolomics, lipidomics helps to comprehensively and systematically identify and quantify lipids to reveal key drivers of disease pathology. The lipid metabolites and pathways strategy (LIPID MAPS) consortium proposed a lipid classification system and divided lipids into the following eight categories: (1) fatty acyls (FAs); (2) glycerolipids (GL); (3) glycerophospholipids (GP), including phosphatidylcholine (PC), phosphatidylserine (PS), phosphatidylethanolamine (PE), phosphatidylinositol (PI), phosphatidic acid (PA), and cardiolipin (CL); (4) sphingolipids (SL), including ceramides (Cer), sphingomyelin (SM), and sphingosine (SPH); (5) prenol lipids (PR); (6) sterol lipids (ST); (7) saccharolipids; and (8) polyketides [7-9]. Apart from acting as constituents of biological structural components and participating in signal transduction, lipids also bind proteins to enable expansion of the metabolic regulatory network [10].

The diversity of lipid structures and the complexity of analytical methods are bottlenecks in systematic studies. With the development of high-throughput and highprecision technologies that rely on liquid chromatography and tandem MS, research on lipid function and metabolic regulation has advanced to the stage of omics. Targeted quantitative lipidomics aids detection of the precise content of specific substances to help provide diversified data for the potential discovery of biomarkers and drug targets $[11,12]$.

\section{Methods}

\section{Study participants}

All 10 pairs of tumor tissues and adjacent normal tissues were obtained from the Urology Department, Henan Provincial People's Hospital. The study was approved by the Medical Ethics Committee of Henan Provincial People's Hospital (no. 2019074) and was conducted in accordance with the Declaration of Helsinki. None of the patients involved in the study presented with any major underlying disease (Table 1).

\section{Sample preparation and extraction}

The samples were measured by weight $(20 \mathrm{mg}$ each) and were then added to $1 \mathrm{~mL}$ lipid extract (methyl tert-butyl ether $/$ methanol $=3 / 1, v / v$, mixed with the internal standard). The internal standards were listed in Table 2. With the addition of steel balls, the mixtures were

Table 1 Clinical information of 10 patients

\begin{tabular}{|c|c|}
\hline Characteristics & Value $\mathrm{N}(\%)$ or Mean \pm SD \\
\hline Age & $54.00 \pm 10.40$ \\
\hline Sex (Male) & $10(80 \%)$ \\
\hline $\mathrm{T} 1 / \mathrm{T} 2$ States & $7 / 3$ \\
\hline Tumor diameter (cm) & $5.03 \pm 2.40$ \\
\hline Hypertension & $10(10 \%)$ \\
\hline Cigarette smoking & $10(10 \%)$ \\
\hline $\mathrm{ALT}, \mathrm{U} / \mathrm{L}$ & $20.92 \pm 14.40$ \\
\hline AST, U/L & $21.58 \pm 7.49$ \\
\hline $\mathrm{TP}, \mathrm{g} / \mathrm{L}$ & $64.07 \pm 10.10$ \\
\hline TBIL, $\mu \mathrm{mol} / \mathrm{L}$ & $10.60 \pm 6.08$ \\
\hline$A L P, U / L$ & $72.37 \pm 22.34$ \\
\hline GGT, U/L & $26.01 \pm 13.68$ \\
\hline TBA, $\mu \mathrm{mol} / \mathrm{L}$ & $1.94 \pm 1.21$ \\
\hline $\mathrm{CHE}, \mathrm{KU} / \mathrm{L}$ & $7.94 \pm 2.85$ \\
\hline $\mathrm{LDH}, \mathrm{U} / \mathrm{L}$ & $215.38 \pm 42.83$ \\
\hline GLDH-D, U/L & $3.89 \pm 1.75$ \\
\hline NEFA-D, mmol/L & $0.28 \pm 0.17$ \\
\hline $\mathrm{CHOL}, \mathrm{mmol} / \mathrm{L}$ & $5.10 \pm 0.64$ \\
\hline $\mathrm{TG}, \mathrm{mmol} / \mathrm{L}$ & $1.83 \pm 0.23$ \\
\hline $\mathrm{HDL}-\mathrm{C}, \mathrm{mmol} / \mathrm{L}$ & $1.11 \pm 0.13$ \\
\hline LDL-C, mmol/L & $3.36 \pm 0.53$ \\
\hline APO-A1, g/L & $1.12 \pm 0.23$ \\
\hline APOB100, g/L & $1.07 \pm 0.20$ \\
\hline $\mathrm{LPa}, \mathrm{mg} / \mathrm{dL}$ & $4.40 \pm 1.98$ \\
\hline UREA, mmol/L & $5.78 \pm 1.49$ \\
\hline CREA, $\mu \mathrm{mol} / \mathrm{L}$ & $103.50 \pm 39.03$ \\
\hline $\mathrm{UA}, \mu \mathrm{mol} / \mathrm{L}$ & $339.33 \pm 74.27$ \\
\hline GLU, mmol/L & $5.78 \pm 1.18$ \\
\hline
\end{tabular}

ALT: alanine aminotransferase; AST: aspartate aminotransferase; TP: total protein; TBIL: total bilirubin; ALP: alkaline phosphatase; GGT: glutamyl transferase; TBA: total bile acid; CHE: cholinesterase; LDH: lactate dehydrogenase; GLDH-D: glutamate dehydrogenase; NEFA-D: non-estesterified fatty acid; CHOL: cholesterol; TG: triglycerides; HDL-C: high density lipoprotein; LDL-C: low density lipoprotein; APO-A1: Apolipoprotein-A1; APOB100: Apolipoprotein B100; LPa: lipoprotein; CREA: Creatinine; UA: Uric acid; GLU: Glucose 
Table 2 The internal standard used in this study

\begin{tabular}{|c|c|c|c|}
\hline Glass & Abbreviations & internal standards & Concentration $(\mathrm{nmol} / \mathrm{mL}, \mu \mathrm{M})$ \\
\hline Free fatty acid & FFA & FFA(18:2)-d11 & 0.2 \\
\hline Acylcarnitine & CAR & $\operatorname{CAR}(16: 0)-d 3$ & 0.2 \\
\hline Eicosanoids & Eicosanoid & 5S-HETE-d8 & 0.04 \\
\hline Cholesterol & Cho & Cho-d7 & 5 \\
\hline Cholesteryl ester & CE & $C E(18: 1)-d 7$ & 2 \\
\hline Bile Acid & BA & GCDCA-d4 & 0.04 \\
\hline Sphingosine & $\mathrm{SPH}$ & SPH(18:1)-d7 & 0.04 \\
\hline Ceramide & Cer & Cer(d18:1(d7)/18:0) & 0.2 \\
\hline Ceramide 1-phosphates & CerP & CerP(d18:1/8:0) & 0.4 \\
\hline Hexosylceramide & HexCer & HexCer(d18:1(d5)/18:0) & 0.4 \\
\hline Sphingomyelin & SM & SM(d18:1(d9)/15:0) & 0.2 \\
\hline Diacylglycerol & DG & DG(17:0/17:0)_d5 & 0.2 \\
\hline Triacylglycerol & TG & TG(17:0/17:1/17:0)_d5 & 0.2 \\
\hline Lysophophatidylcholine & LPC & $\operatorname{LPC}(16: 0)-d 31$ & 0.2 \\
\hline alkyl-Lysophophatidylcholine & LPC-O & LPC(16:0)-d31 & 0.2 \\
\hline Lysophosphatidylethanolamine & LPE & LPE(14:0) & 0.2 \\
\hline alkenyl-Lysophosphatidylethanolamine & LPE-P & LPE(14:0) & 0.2 \\
\hline Lysophosphatidylglycerol & LPG & LPG(14:0) & 0.2 \\
\hline Lysophosphatidylinositol & LPI & $\operatorname{LPI}(17: 1)$ & 0.2 \\
\hline Lysophosphatidylserine & LPS & $\operatorname{LPS}(17: 1)$ & 0.2 \\
\hline Phosphatidylcholine & PC & $P C(16: 0(d 31) / 18: 1)$ & 0.2 \\
\hline alkyl-glycerophosphocholines & PC-O & $P C(16: 0(d 31) / 18: 1)$ & 0.2 \\
\hline Phosphatidylethanolamine & $\mathrm{PE}$ & $\operatorname{PE}(16: 0(d 31) / 18: 1)$ & 0.2 \\
\hline alkenyl-glycerophosphoethanolamines & PE-P & $\operatorname{PE}(16: 0(d 31) / 18: 1)$ & 0.2 \\
\hline Phosphatidylglycerol & PG & $P G(16: 0(d 31) / 18: 1)$ & 0.4 \\
\hline Phosphatidylinositol & $\mathrm{Pl}$ & $\mathrm{PI}(16: 0(\mathrm{~d} 31) / 18: 1)$ & 0.2 \\
\hline Phosphatidylserine & PS & $\operatorname{PS}(16: 0(d 31) / 18: 1)$ & 0.4 \\
\hline Coenzyme Q & CoQ & CoQ10-d9 & 0.4 \\
\hline
\end{tabular}

homogenized using a ball mill. After subjection to vortexing for $2 \mathrm{~min}$ and after sonication for $5 \mathrm{~min}, 200 \mu \mathrm{L}$ of water was added. The samples were centrifuged for $10 \mathrm{~min}$ at $12000 \mathrm{rpm}$. The supernatant was aspirated and concentrated, and reconstituted with $200 \mu \mathrm{L}$ of phase B (acetonitrile/isopropanol (10/90, v/v) with $0.1 \%$ formic acid and $10 \mathrm{mmol} / \mathrm{L}$ ammonium formate).

\section{Ultra-performance liquid chromatography (UPLC) conditions}

The ExionLC ${ }^{\mathrm{Tm}}$ AD (AB Sciex, Framingham, USA) UPLC instrument was used by considering conditions as follows: (1) chromatographic column: the Thermo Accucore C30 column $(2.6 \mu \mathrm{m}, 100 \mathrm{~mm} \times 2.1 \mathrm{~mm} \mathrm{ID)}$; (2) mobile phase: phase A, acetonitrile/water $(60 / 40, \mathrm{v} / \mathrm{v}$, with $0.1 \%$ formic acid and $10 \mathrm{mmol} / \mathrm{L}$ ammonium formate); phase $\mathrm{B}$, acetonitrile/isopropanol (10/90, v/v, with $0.1 \%$ formic acid and $10 \mathrm{mmol} / \mathrm{L}$ ammonium formate);
(3) gradient washing program: 80/20 (phase $\mathrm{A} / \mathrm{B}, \mathrm{v} / \mathrm{v}$ ) at 0 min, 70/30 (phase $\mathrm{A} / \mathrm{B}, \mathrm{v} / \mathrm{v}$ ) at $2 \mathrm{~min}, 40 / 60$ (phase A/ $\mathrm{B}, \mathrm{v} / \mathrm{v}$ ) at $4 \mathrm{~min}, 15 / 85$ (phase $\mathrm{A} / \mathrm{B}, \mathrm{v} / \mathrm{v}$ ) at $9 \mathrm{~min}, 10 / 90$ (phase $\mathrm{A} / \mathrm{B}, \mathrm{v} / \mathrm{v}$ ) at $14 \mathrm{~min}, 5 / 95$ (phase $\mathrm{A} / \mathrm{B}, \mathrm{v} / \mathrm{v}$ ) at 15.5 min, 5/95 (phase A/B, v/v) at $17.3 \mathrm{~min}, 80 / 20$ (phase A/ $\mathrm{B}, \mathrm{v} / \mathrm{v}$ ) at $17.5 \mathrm{~min}, 80 / 20$ (phase $\mathrm{A} / \mathrm{B}, \mathrm{v} / \mathrm{v}$ ) at $20 \mathrm{~min}$; (4) the flow rate was $0.35 \mathrm{~mL} / \mathrm{min}$, the column temperature was $45^{\circ} \mathrm{C}$, and the injection volume was $2 \mu \mathrm{L}$.

\section{Electrospray ionization-MS/MS conditions}

The QTRAP ${ }^{\circ} 6500+$ (AB Sciex, Framingham, USA) mass spectrometer was used. The electrospray ionization source temperature was $500{ }^{\circ} \mathrm{C}$. The MS voltage values were $5500 \mathrm{~V}$ (positive ion mode) and $-4500 \mathrm{~V}$ (negative ion mode). The pressure of ion source gas 1 was $45 \mathrm{psi}$, while that of ion source gas 2 was $55 \mathrm{psi}$; the pressure of the curtain gas was 35 psi. Each ion pair was scanned 
using optimal declustering potential and collision energy settings in the triple quadrupole.

\section{Data preprocessing}

The MetWare Database (MWDB) was constructed based on the information available on standard products. Quantification was performed in the multiple reaction monitoring (MRM) mode. Only specified ions were collected. The chromatographic peaks of all targets were integrated, and quantitative analysis was performed using the internal standard.

A part of each sample was mixed to prepare a quality control, which was then analyzed using the total ion current and MRM metabolite detection multimodal graph (extracted ion current). MS data were processed using the Analyst 1.6.3 software based on the local lipid database. The MS peaks detected in different samples for each substance were calibrated to ensure accurate quantification.

\section{Lipid quantitative analysis}

Different concentrations $(0.2 \mathrm{nmol} / \mathrm{L}, \quad 0.5 \mathrm{nmol} / \mathrm{L}, \quad 1$ $\mathrm{nmol} / \mathrm{L}, 2 \mathrm{nmol} / \mathrm{L}, 5 \mathrm{nmol} / \mathrm{L}, 10 \mathrm{nmol} / \mathrm{L}, 20 \mathrm{nmol} / \mathrm{L}, 50$ $\mathrm{nmol} / \mathrm{L}, \quad 100 \mathrm{nmol} / \mathrm{L}, \quad 200 \mathrm{nmol} / \mathrm{L}, \quad 500 \mathrm{nmol} / \mathrm{L}, \quad 1000$ $\mathrm{nmol} / \mathrm{L}, 2000 \mathrm{nmol} / \mathrm{L}, 5000 \mathrm{nmol} / \mathrm{L}$, and $10,000 \mathrm{nmol} / \mathrm{L}$ ) of standard solutions were prepared using a mixture of dichloromethane/methanol to obtain data on the peak intensity and the corresponding quantitative signals. The chromatographic peak area indicates the relative content of the corresponding substance; this information was substituted into the linear equation and calculation formula (Table 3-4). The following calculation formula was subjected to unit conversion, and the sample content could be obtained by directly substituting the corresponding values in the generated standard curves.

$$
\mathrm{X}=(0.001 \times \mathrm{c} \times \mathrm{V} \times \mathrm{v} 1) / \mathrm{v} 2 / \mathrm{m}
$$

$\mathrm{X}$ : the content of lipid in the sample (nmol/g);

c: the concentration value obtained by substituting the integrated peak area ratio in the sample into the standard curve $(\mathrm{nmol} / \mathrm{mL})$;

$\mathrm{V}$ : volume of the reconstituted solution $(\mu \mathrm{L})$;

v1: volume of the sample extraction solution $(\mu \mathrm{L})$;

v2: volume of the collected supernatant $(\mu \mathrm{L})$; and.

$\mathrm{m}$ : sample mass (g).

\section{Results}

\section{Lipid composition analysis}

Qualitative analysis was performed after the completion of lipid extraction and MWDB establishment. The linear equations and correlation coefficients of the standard curves are presented in Table 2-4. The calculation
Table 3 Standard curve linear equation

\begin{tabular}{|c|c|c|c|c|}
\hline Class & Equation & $\mathbf{r}$ & LLOQ & ULOQ \\
\hline BA & $y=5.89032 x+0.00349$ & 0.99952 & 0.001 & 1 \\
\hline CAR & $y=10.63664 x-9.00378 e-4$ & 0.99178 & 0.005 & 5 \\
\hline CE & $y=4.15246 x-0.00124$ & 0.99310 & 0.01 & 5 \\
\hline Cer & $y=2.90771 x+0.00126$ & 0.99628 & 0.002 & 2 \\
\hline CerP & $y=0.14978 x+7.83392 e-5$ & 0.99815 & 0.005 & 2 \\
\hline Cho & $y=4.27736 x+0.02240$ & 0.99768 & 0.005 & 5 \\
\hline CoQ & $y=3.64824 x+1.73992$ & 0.99749 & 0.002 & 2 \\
\hline DG & $y=7.54751 x+0.04692$ & 0.99412 & 0.002 & 2 \\
\hline Eicosanoid & $y=61.65750 x+0.08742$ & 0.99661 & 0.001 & 1 \\
\hline FFA & $y=22.05858 x-0.21591$ & 0.99297 & 0.02 & 10 \\
\hline HexCer & $y=1.40675 x-2.86002 e-5$ & 0.99152 & 0.002 & 2 \\
\hline LPC & $y=2.87925 x-0.00565$ & 0.99009 & 0.01 & 5 \\
\hline LPC-O & $y=2.87925 x-0.00565$ & 0.99009 & 0.01 & 5 \\
\hline LPE & $y=0.43538 x-0.00138$ & 0.99562 & 0.02 & 5 \\
\hline LPE-P & $y=0.43538 x-0.00138$ & 0.99562 & 0.02 & 5 \\
\hline LPG & $y=0.62714 x-1.52689 e-5$ & 0.99848 & 0.005 & 2 \\
\hline LPI & $y=0.06717 x+0.00722$ & 0.99669 & 0.002 & 2 \\
\hline LPS & $y=0.10692 x+2.42176 e-5$ & 0.99127 & 0.01 & 2 \\
\hline PC & $y=1.39542 x-6.09826 e-4$ & 0.99651 & 0.002 & 10 \\
\hline PC-O & $y=1.39542 x-6.09826 e-4$ & 0.99651 & 0.002 & 10 \\
\hline$P E$ & $y=14.19927 x-0.02853$ & 0.99327 & 0.01 & 5 \\
\hline PE-P & $y=1.01408 x-0.00815$ & 0.99613 & 0.02 & 5 \\
\hline PG & $y=6.97289 x+0.01424$ & 0.99033 & 0.01 & 10 \\
\hline $\mathrm{Pl}$ & $y=3.05988 x-0.15491$ & 0.99717 & 0.02 & 5 \\
\hline PS & $y=6.52668 x-0.37092$ & 0.99437 & 0.01 & 10 \\
\hline SM & $y=0.68841 x-5.22709 e-4$ & 0.99110 & 0.002 & 10 \\
\hline $\mathrm{SPH}$ & $y=1.80406 x+4.28477 e-4$ & 0.99513 & 0.005 & 2 \\
\hline TG & $y=1.33356 x+5.11722 e-4$ & 0.99125 & 0.005 & 10 \\
\hline
\end{tabular}

Class: lipid classification; Equation: linear equation; $r$ : the correlation coefficient; LLOQ (nmol/mL): lower limit of quantification; ULOQ $(\mathrm{nmol} / \mathrm{mL})$ : upper limit of quantification

formula was further introduced to obtain information on the absolute content. A total of 28 lipid subclasses, and their corresponding compounds, were detected (Fig. 1A). The lipid subclass presenting with the highest number of compounds was triacylglycerol (TG). The total content of quantified lipids was calculated by considering the sum of the contents of all lipid compounds in the same sample, and value of the summation was significantly higher in tumor tissues than that estimated in normal tissues (Fig. 1B).

Principal component analysis (PCA) is a common and unsupervised pattern-recognition multi-dimensional statistical analysis that is used to transform potentially correlated variables into linearly uncorrelated variables through orthogonal transformation [13]. Partial least squares-discriminant analysis (PLS-DA) is a multivariate 
Table 4 The specific lipid specie that was used to generate the calibration curve

\begin{tabular}{|c|c|c|c|c|}
\hline Class & Lipid name & CAS number & Supplier & Article number \\
\hline FFA & $F A(18: 2)$ & $60-33-3$ & sigma-Aldrich & L1376 \\
\hline CAR & $\operatorname{CAR}(16: 0)$ & $2364-67-2$ & Supelco & 91,503 \\
\hline Eicosanoid & 5S-HETE & $73,307-52-5$ & cayman & 34,210 \\
\hline Cho & cholesterol & $57-88-5$ & sigma-Aldrich & C3045 \\
\hline CE & CE(18:2) & $604-33-1$ & sigma-Aldrich & C0289 \\
\hline BA & Glycochenodeoxycholic acid & $16,564-43-5$ & sigma-Aldrich & G0759 \\
\hline $\mathrm{SPH}$ & $\mathrm{SPH}(18: 1)$ & $213-78-4$ & Avanti & \\
\hline Cer & Cer(d18:1/17:0) & $67,492-21-4$ & Avanti & $860517 P$ \\
\hline CerP & CerP(d18:1/16:0) & $2,146,303-22-9$ & Avanti & $860533 P$ \\
\hline HexCer & HexCer(d18:1/16:0) & $2,260,795-77-3$ & Cayman & 26,009 \\
\hline SM & $\mathrm{SM}(\mathrm{d} 18: 1 / 17: 0)$ & $121,999-64-2$ & Avanti & $860585 P$ \\
\hline DG & $D G(17: 0 / 17: 0)$ & $98,896-81-2$ & Cayman & 26,942 \\
\hline TG & TG(17:0/17:0/17:0) & $2438-40-6$ & sigma-Aldrich & T2151 \\
\hline LPC & $\operatorname{LPC}(17: 0)$ & 50,930-23-9 & Avanti & $855676 \mathrm{P}$ \\
\hline LPC-O & $\operatorname{LPC}(17: 0)$ & 50,930-23-9 & Avanti & $855676 \mathrm{P}$ \\
\hline LPE & LPE(18:0) & $69,747-55-3$ & Avanti & $856715 P$ \\
\hline LPE-P & LPE(18:0) & $69,747-55-3$ & Avanti & $856715 P$ \\
\hline LPG & LPG(18:0) & $326,495-23-2$ & Avanti & $858214 \mathrm{P}$ \\
\hline LPI & $\operatorname{LPI}(18: 1)$ & $799,268-53-4$ & Avanti & $850149 P$ \\
\hline LPS & LPS(18:1) & 326,589-90-6 & Avanti & $858143 P$ \\
\hline PC & $P C(17: 0 / 17: 0)$ & 70,897-27-7 & Avanti & $850360 P$ \\
\hline PC-O & PC(17:0/17:0) & 70,897-27-7 & Avanti & $850360 P$ \\
\hline PE & $P E(17: 0 / 17: 0)$ & $140,219-78-9$ & Avanti & $830756 \mathrm{P}$ \\
\hline PE-P & $P E(P-18: 0 / 18: 1)$ & $144,371-68-6$ & Avanti & $852758 \mathrm{P}$ \\
\hline PG & $P G(17: 0 / 17: 0)$ & $799,268-52-3$ & Avanti & $830456 \mathrm{P}$ \\
\hline PI & $P S(16: 0 / 18: 1)$ & $321,863-21-2$ & Avanti & $840034 \mathrm{P}$ \\
\hline PS & $\mathrm{PI}(16: 0 / 18: 1)$ & 50,730-13-7 & Avanti & $850142 \mathrm{P}$ \\
\hline $\mathrm{CoQ}$ & CoQ10 & $303-98-0$ & Supelco & 7386 \\
\hline
\end{tabular}

statistical analysis with supervised pattern recognition that helps maximize the distinction between groups and aids the discovery of different metabolites. Orthogonal partial least squares discriminant analysis (OPLS-DA) is used to connect orthogonal signal correction with PLS-DA to generate score maps of each group to further highlight the differences [14]. PCA analysis was performed to determine the separation trend between the groups (Fig. 1C). The OPLS-DA model was established by using the OPLSR. Anal function in the MetaboAnalyst $\mathrm{R}$ software package to compare the degree of variability between the groups and between the samples within the group (Fig. 1D). $R^{2} X$ and $R^{2} Y$ represent the interpretation rates of the $\mathrm{X}$ and $\mathrm{Y}$ matrices, respectively. The predictive ability is represented by $\mathrm{Q}^{2}$. The evaluation shows that the OPLS-DA model is ideal and stable (Fig. 1E-F).

\section{Differences in lipid subclass content}

Functional research on lipids is mainly conducted and expressed in units of subclasses. Different lipid subclasses demonstrate evident differences in their biological functions. Acylcarnitine (CAR), cholesteryl ester (CE), diacylglycerol (DG), SPH, alkylglycerophosphocholines (PC-O), alkenylglycerophosphoethanolamines (PE$\mathrm{P})$, and cholesterol (Cho) presented with significantly higher levels in tumors than those observed in normal samples. Additionally, the content of bile acid (BA) and lysophosphatidylserine (LPS) in tumor tissues was lower than that in normal tissue (Fig. 2A). There was no significant difference in the content of other types of lipids (Fig. S1).

Analysis of the dynamic distribution range of lipid content revealed the lipid molecules presenting with the lowest and highest levels, as well as highlighted changes in the span of lipid content. In normal samples, 3- 


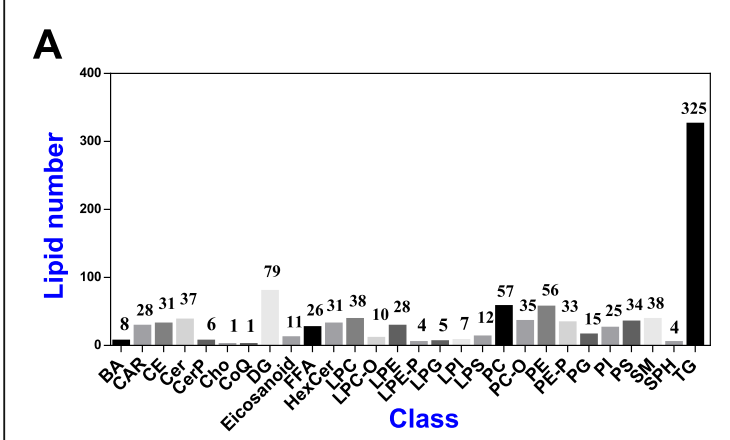

D

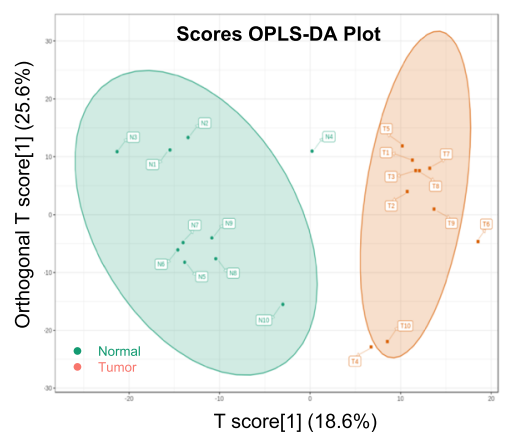

B

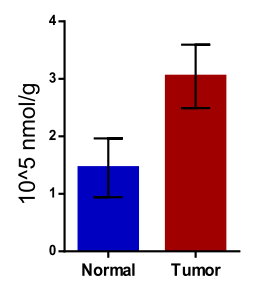

$\mathbf{E}$

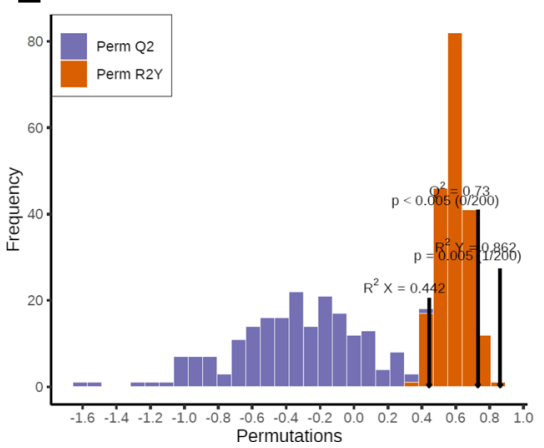

C

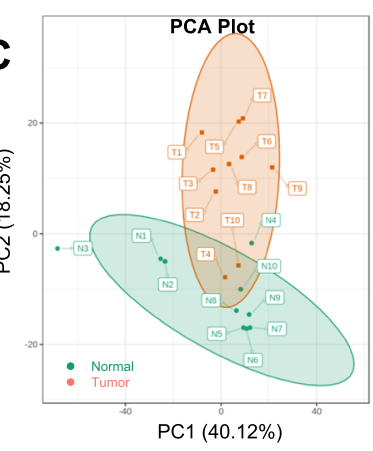

$\mathbf{F}$

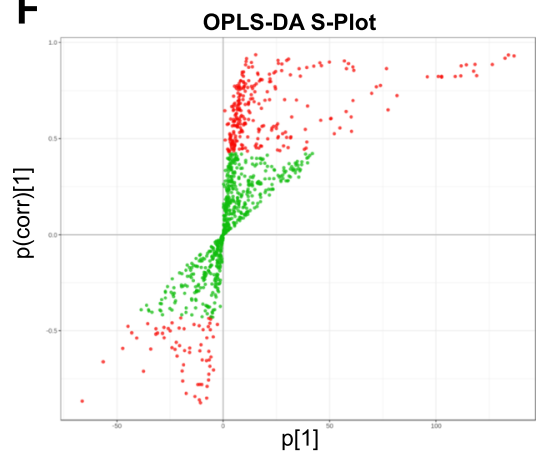

Fig. 1 Lipid identification. A The type and number of identified lipids. B The total content of lipid molecules. C The PCA analysis on tumor and normal samples. D OPLS-DA score chart. The abscissa represents the predicted principal component and abscissa direction indicates the gap between groups. The ordinate represents the orthogonal principal component and the ordinate direction indicates the gap within the group. $\mathbf{E}$ The verification diagram OPLS-DA model. R2X $=0.442, \mathrm{R} 2 \mathrm{Y}=0.862$, Q2 $=0.73, P<0.005$. F S-plot of OPLS-DA model. The abscissa represents the covariance between the principal component and the lipid, and the ordinate represents the correlation coefficient between the principal component and the lipid. The red points indicate that the VIP value of these lipids is greater than or equal to 1, and the green points indicate that the VIP value of these lipids is less than 1

hydroxylaurylcarnitine exhibited the lowest levels and triglyceride-TG (52:4)_18:2 exhibited the highest levels. In tumor tissues, the lipid with the lowest content was identified as tridecanoyl carnitine, and the lipid with the highest content was identified as cholesterol lipid-CE (18:2) (Fig. 2B).

\section{Lipid chain length analysis}

The length of the lipid chain is defined as the sum of the carbon atoms in the fatty acid chain of the lipid molecule. In addition to the lipid content, chain length is closely related to lipid function. The chain length can affect the thickness of the plasma membrane, which in turn affects the fluidity of the cell membrane, the activity and function of the relevant lipid transport protein, and the target protein [15].

The data on the levels of lipid compounds presenting with the same chain length were added together, and the differences in the presence of different chain lengths were noted. Compared with the normal group, the content of CAR in the tumor group was found to be increased significantly at chain lengths of $12,16,18$, and 20 , but was reduced by a chain length of 22 . For all chain lengths, the $\mathrm{CE}$ content observed in the tumor group was significantly higher than that noted in the normal group. The content of DG in the tumor group increased with chain lengths of $32,34,36$, and 42 , and there was no significant difference between other chain lengths. Increased content of PE in chain lengths of 40, 41,42 , and 44 , and decreased in chain lengths of 30,33 , 34 , and 36 , were observed in tumor samples. In tumors, lipid contents were decreased in TG with lengths of 36, 38 , 41, and 43, as well as in alkenyllysophosphatidylethanolamine (LPE-P) and BA (Fig. 3). The chains in the other subclasses between groups were measured and the significant differences are marked with an asterisk (Fig. S2).

\section{Lipid chain unsaturation analysis}

The degree of unsaturation of the lipid chain is defined as the sum of the number of double bonds in the fatty acid chain of the lipid molecule. The saturation of cell membrane lipids affects the fluidity of the membrane, which in turn affects the proliferation and invasiveness of tumor cells [16]. 

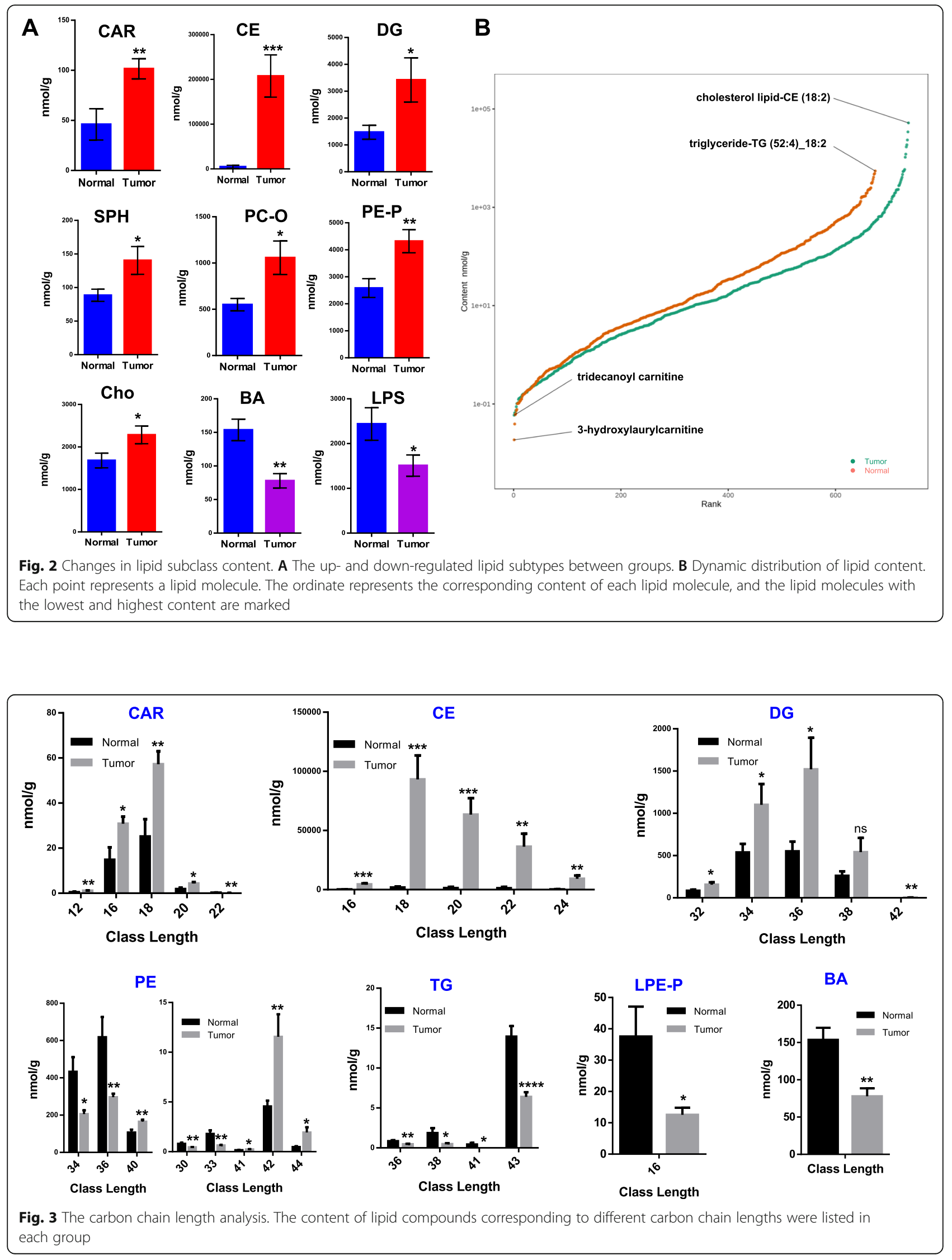
The data on the levels of lipid compounds with the same number of unsaturated bonds were added. Compared with the normal group, it was observed that the lipid content of all unsaturated bonds in CAR and CE increased significantly in the tumor group. The content of lipid compounds with a partial number of unsaturated bonds in other lipid types showed a significant increase or decrease in tumors (Fig. 4, Fig. S3). Lipid chain length and unsaturation level affect the mechanical properties of the respective biological macromolecules. Studies have found that a gradual accumulation of specific longchain fatty acids (LCFAs) in CD8+ T cells in the pancreas not only disrupts mitochondrial function, but also promotes the TCA cycle through the $\beta$ oxidation process of FA [17]. The types of LCFAs and lipids with different saturations may provide clues for the maintenance of tumor progression and immune cell metabolic reprogramming in the tumor microenvironment [17].

\section{Screening of differentially expressed lipids}

Differential lipids were screened based on the fold change (FC) and variable importance in projection (VIP) values. Compared with the normal group, the differences were considered significant in the tumor groups with $\mathrm{FC} \geq 2$ and $\mathrm{FC} \leq 0.5$, respectively. Lipids with VIP $\geq 1$ were regarded as significantly different.

The FC in each group was compared and calculated according to their binary logarithm. The top 20 upregulated and downregulated lipids were ranked according to a VIP $\geq 1$. The lipids with the most upregulated expression were $\mathrm{CE}(22: 1) \quad(\mathrm{FC}=6.83), \mathrm{CE}(24: 1)$ $(\mathrm{FC}=6.74)$, and $\mathrm{CE} \quad(20: 1) \quad(\mathrm{FC}=6.61)$. Most lipids among the top 20 upregulated lipids were identified as cholesteryl ester, except for TG (60:0)_20:0 FC=5.16) and DG (18:1_24:0) $(\mathrm{FC}=4.26)$. Additionally, the lipids with most downregulated expression were TG (46:3)_18: $1(\mathrm{FC}=4.87)$, TG $(50: 5) \_14: 1 \quad(\mathrm{FC}=4.84)$, and TG $(46$ : 3)_18:2 (FC $=4.83)$. Most lipids among the top 20 downregulated lipids were TG, except for lysophosphatidylethanolamine (LPE) $(18: 0 / 0: 0) \quad(\mathrm{FC}=3.57) \quad$ (Fig. 5A, Supplementary Table 1). The top 20 lipids with the greatest VIP value in each group in the OPLS-DA model were selected, and expression levels of all were found to be upregulated (Fig. 5B, Supplementary Table 2).

A total of 109 upregulated lipids and 51 downregulated lipids are indicated in red and green, respectively, in the volcano plot (Fig. 5C). Each point represents a metabolite. The closeness of significantly different lipids was measured via differential lipid correlation analysis to further understand their mutual adjustment relationship. Pearson correlation analysis was performed for the significantly different lipids. The top 50 differential lipids with the greatest VIP values were selected (Fig. 5D). Interestingly, there is a more obviously negative correlation between several types of TG with other lipids.

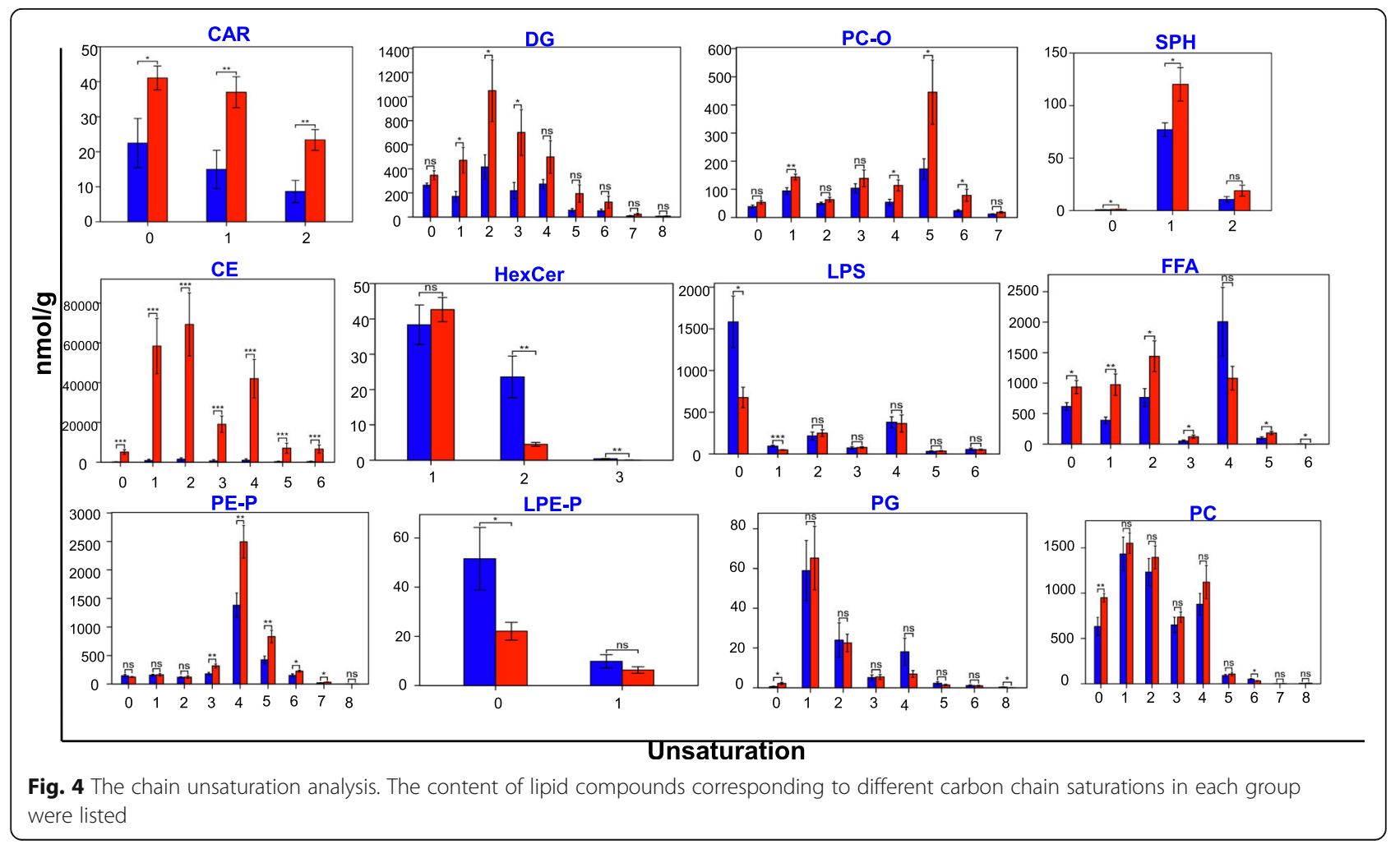




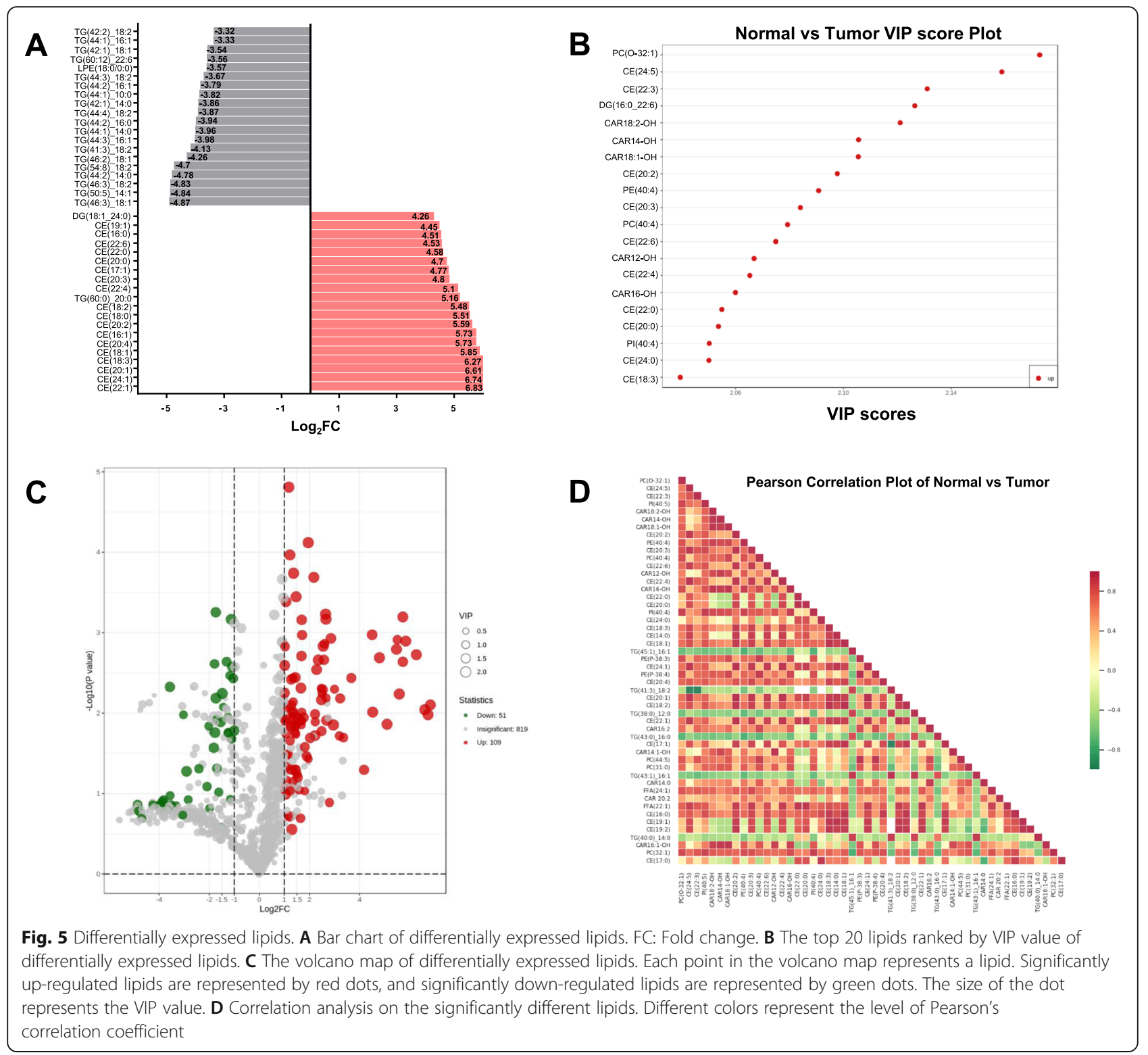

\section{Discussion}

Accurate identification and absolute quantification of lipids are important for the comprehensive study of lipid metabolism. Fatty acid oxidation (FAO) is essential for tumor metabolic reprogramming, a mechanism which provides the necessary energy and biological intermediate products [18]. The upregulated FAO in tumors contributes to tumor growth and progression, and to the development of the malignant phenotype characterized by aggressive, metastatic, and drug resistance traits [19$24]$. In the $\beta$-oxidation process, FAs are activated and degraded after binding to coenzyme A (CoA) in the cytoplasm. Inhibition of $\beta$-oxidation decreases FA metabolism, preventing hydroperoxide formation and ferroptosis in a manner dependent on glutathione or glutathione peroxidase in ccRCC [25]. Carnitine palmitoyltransferase 1 (CPT1) catalyzes the transfer of longchain fatty acyl-CoA into CAR, which is then carried by the carnitine translocator (CAT) across the inner mitochondrial membrane. CPT2 catalyzes the conversion of long-chain CAR into long-chain acyl-CoA. High expression of CPT1 has been reported in breast cancer [26], lung cancer [27], gastric cancer [28], prostate cancer [29], ovarian cancer [30], nasopharyngeal cancer [31] and chronic lymphoblastic leukemia [32]. CPT1 is considered the rate-limiting enzyme for FAO, and the level of CAR reflects the degree of FAO to a certain extent [33]. Cholesterol is not only an important component of the membrane structure, but also serves as a precursor for BAs, sterol hormones, vitamins, and oxidized 
cholesterol [34]. Tumor cells hijack and store excess cholesterol contents in LD in the form of CE to provide energy, to promote tumor growth, and to increase metastasis of prostate and pancreatic tumors [35, 36]. Blockade of cholesterol intake via inactivation of the liver $\mathrm{X}$ receptors causes the death of malignant brain cancer cells, resulting in a positive therapeutic effect [37]. DG is produced by the phosphatase enzyme reaction through phosphatidic acid in the endoplasmic reticulum or via the decomposition of TG during lipolysis [38]. As a secondary messenger, DG activates a signal cascade reaction to promote tumor growth [39]. The quantitative lipidomic results in this study showing an accumulation of CAR, CE, and DG, which can be mutually supported by the conclusion of the increase of upstream metabolic enzymes in these literatures. In addition to the detection of peripheral blood content, the study of these metabolite levels in tumors is conducive to the in-depth study of metabolic reprogramming driven by endogenous and exogenous factors and is valuable for the exploration of combined therapy related to the immune regulation of the ccRCC tumor microenvironment.

After combining with cell membranes to release arachidonic acid, fat-soluble BA promotes reactive oxygen species (ROS) production and induces DNA damage [40]. The functions of BA in mediating inflammation, in promoting proliferation, and in inhibiting apoptosis proceed by a series of signal transductions [41]. Intestinal bacteria modify BAs that enter the intestine, promoting their disintegration. The resulting metabolites promote the differentiation of anti-inflammatory Treg cells and inhibit the proliferation of pro-inflammatory Th17 cells, thereby regulating the immune response [42, 43]. The content of BA in ccRCC and the regulation of tumor growth and immune cells have not been studied thus far. The significantly lower BA content reported in the present study, and its function in tumor tissues, merit further confirmation.

\section{Comparisons with other studies and what does the current work add to the existing knowledge}

Apart from exhibition of genetic mutations and epigenetic regulation [44], ccRCC is a metabolic disease that involves metabolic reprogramming during tumorigenesis and progression [45]. Lipid accumulation in ccRCC is related to the absorption and excretion of lipid metabolites [46, 47]. The role of considerable amounts of lipid droplets (LDs) accumulated in ccRCC remains controversial [48]. Abnormal hypoxia inducible factor (HIF) expression caused by VHL gene deletion has been shown to promote tumor angiogenesis, glycolysis, and metastasis [49]. Different isoforms of phospholipid-binding protein AnxA3 help modulate LD storage in ccRCC cell lines [47]. The number of LDs is closely related to the concentration of glucose in the cells. Fatty acid synthesis is vigorous and, under conditions when glucose concentration is sufficient, TG is synthesized and stored in LD [50]. The metabolite lactic acid under anaerobic conditions is used as an energy carrier for mutual transmission within and between tissues in lung and pancreatic cancers [51]. There is a need to utilize highly advanced metabolic research methods to explore the increased FA uptake and synthesis, glycolysis enzyme expression, glycolysis paradox (Warburg effect), pentose phosphate pathway, uptake of external glutamine and arginine, and the decreased $\beta$-oxidation of FA and oxidative phosphorylation [52].

Combined analysis of renal cancer proteomics and non-targeted metabolomics has helped reveal gradedependent metabolic reprogramming $[33,53]$. The detection of metabolites using NMR illustrates an overall signature in the urine samples of patients [54, 55]. An HIF-1 targeted gene, NADH dehydrogenase (ubiquinone) 1 alpha subcomplex 4-like 2 (NDUFA4L2), was overexpressed in ccRCC tumor samples and was found to promote proliferation, migration, and drug resistance, based on a combination of untargeted metabolomic and transcriptomic analyses [56]. MS-dependent untargeted lipidomic research has further helped identify the enrichment of polyunsaturated FAs (PUFAs) based on the analysis of long-chain FAs (LCFAs) [57]. Compared to the existing studies, the present study revealed quantitative detection of a variety of lipid metabolites in ccRCC at one time and provided more comprehensive data support for ccRCC progression based on more detailed lipid profile information.

\section{Study strengths and limitations}

Lipid signaling molecules participate in proliferation, death signaling, and tumor metabolism [10]. Lipidomic research is conducted by including differential lipid screening, regulation of lipid function, and lipid network construction. Non-targeted lipidomics is unbiased and systematically reflects the lipid characteristics of living bodies. The repeatability of non-targeted lipidomics is poor and the linear range is limited. Targeted quantitative lipidomic research, as performed in the present study, benefits from wide coverage, high throughput, reproducibility, sensitivity, and accuracy. It is, however, a biased analysis based on specific types of lipids; hence, exogenous lipids are necessary for consideration as internal standards. The existing research methods implemented may destroy the physiological structure of lipids during sample extraction and preparation; this may cause significant differences in the results. Thus, it is imperative to modify the extraction steps and to 
standardize database construction for different types of biological specimens included and analyzed.

\section{Conclusions}

Tumor cells establish their own malignant proliferation through metabolic reprogramming, which is an important feature that distinguishes them from normal cells. A comprehensive and in-depth characterization of tumor metabolic characteristics provides an opportunity to identify and develop potential tumor diagnosis and treatment targets. Global lipidomic analysis with approaches that change dynamically over time will be used to analyze tumor pathogenesis with greater accuracy. In this project, 28 subclasses of lipids were detected using the UPLC-MS/MS detection platform. Different lipid changes in ccRCC tumor tissues, such as increased CAR, CE, DG, and SPH levels, and a decrease in BA and LPS, may be related to an increase in the components constituting the membrane structure required for cell proliferation and the rearrangement of events in energy metabolism; this aspect warrants further in-depth verification.

\begin{abstract}
Abbreviations
cCRCC: clear cell renal cell carcinoma; MRM: Multiple Reaction Monitoring; UPLC: Ultra-Performance Liquid Chromatography; MS: Mass Spectrometry; TG: Triacylglycerol; DG: Diacylglycerol; PC: Phosphatidylcholine; PE: Phosphatidylethanolamine; CE: Cholesteryl ester; CAR: Acylcarnitine; VIP: Variable Importance in Projection; VHL: von Hippel Lindau; NMR: Nuclear Magnetic Resonance; FA: Fatty acyls; PUFA: polyunsaturated FA; LCFA: long chain FA; NDUFA4L2: NADH dehydrogenase (ubiquinone) 1 alpha subcomplex 4-like 2; GP: Glycerophospholipids; PS: Phosphatidylserine; PI: Phosphatidylinositol; PA: Phosphatidic acid; CL: Cardiolipin;

SL: Sphingolipids; Cer: Ceramides; SM: Sphingomyelin; SPH: Sphingosine; ST: Sterol lipids; PR: Prenol lipids; PK: Polyketides; LD: lipid droplet; HIF: Hypoxia Inducible Factor; PCA: Principal Component Analysis; PLSDA: Partial least squares-discriminant analysis; OPLS-DA: Orthogonal partial least squares discriminant analysis; PC-O: alkylglycerophosphocholines; PEP: alkenylglycerophosphoethanolamines; Cho: Cholesterol; BA: Bile acid; LPS: Lysophosphatidylserine; LPE-P: alkenyl-Lysophosphatidylethanolamine; LPE: Lysophosphatidylethanolamine; FC: Fold change; DA: Differential Abundance; FAO: Fatty acid oxidation; ROS: Reactive oxygen species; CPT1: Carnitine palmitoyltransferase 1; CAT: Carnitine translocator; ALT: alanine aminotransferase; AST: aspartate aminotransferase; TP: total protein; TBIL: total bilirubin; ALP: alkaline phosphatase; GGT: glutamyl transferase; TBA: total bile acid; CHE: cholinesterase; LDH: lactate dehydrogenase; GLDH-D: glutamate dehydrogenase; NEFA-D: nonestesterified fatty acid; CHOL: cholesterol; TG: triglycerides; HDL-C: high density lipoprotein; LDL-C: low density lipoprotein; APO-A1: ApolipoproteinA1; APOB100: Apolipoprotein B100; LPa: lipoprotein; CREA: Creatinine; UA: Uric acid; GLU: Glucose
\end{abstract}

\section{Supplementary Information}

The online version contains supplementary material available at https://doi. org/10.1186/s12944-021-01572-z.

Additional file 1: Fig. S1. The non-significant lipid count between groups. There are no significant differences in all group comparisons. Fig. S2. Chain length of lipid subtypes between groups. Significant differences are marked with an asterisk, and no significant differences are not marked. Fig. $\mathbf{S 3}$ Chain unsaturation of lipid subtypes between groups. Significant differences are marked with an asterisk.
Additional file 2: Supplementary Table 1. Differentially expressed lipids.

Additional file 3: Supplementary Table 2. VIP value.

\section{Acknowledgements}

No applicable.

\section{Authors' contributions}

Research design: Zhifeng Wang, Wen Li; Conducted experiments: Wen Li, Xiaobin Wang, Ning Wang; Performed data analysis: Wen Li, Xianbin Zhang, Peng Gong, Degang Ding; Contributed to the writing of the manuscript: Wen Li, Degang Ding, Zhifeng Wang. The author(s) read and approved the final manuscript.

\section{Funding}

This project was supported by the National Natural Science Foundation of China (No. 82003114) to W.L., the Postdoctoral Research Foundation of China (No. 2020 M682888) to W.L., the Applied Basic Research Project of Sichuan Science and Technology Department (No. 2020YJ0174) to W.L. and

Shenzhen Key Medical Discipline Construction Fund and Sanming Project of Medicine in Shenzhen (No. SZSM202111002) to Peng Gong.

\section{Availability of data and materials}

All data included in this study are available upon request by contact with the corresponding author.

\section{Declarations}

Ethics approval and consent to participate

The study was carried out following the Declaration of Helsinki for experiments involving humans and was approved by the Medical Ethics Committee of Henan Provincial People's Hospital (No. 2019074).

\section{Consent for publication}

Authors provide formal consent to publish work.

\section{Competing interests}

The authors declare no conflict of interest.

\section{Author details \\ ${ }^{1}$ Carson International Cancer Centre, Shenzhen University General Hospital and Shenzhen University Clinical Medical Academy Centre, Shenzhen University, 1098 Xueyuan Road, Shenzhen 518000, Guangdong, China. ${ }^{2}$ Key Laboratory of Optoelectronic Devices and Systems, College of Physics and Optoelectronic Engineering, Shenzhen University, Shenzhen 518060, China. ${ }^{3}$ Health Science Center, School of Medicine, Shenzhen University, Shenzhen 518060, China. ${ }^{4}$ Department of General Surgery, Shenzhen University General Hospital, Xueyuan Road 1098, Shenzhen 518055, China. ${ }^{5}$ Department of Urology, Henan Provincial People's Hospital, Zhengzhou University People's Hospital, Henan University People's Hospital, No. 7 Weiwu Road, Zhengzhou City 450003, Henan Province, China.}

Received: 19 July 2021 Accepted: 29 September 2021

Published online: 13 November 2021

\section{References}

1. Siegel RL, Miller KD, Fuchs HE, Jemal A. Cancer statistics, 2021. CA Cancer J Clin. 2021;71(1):7-33. https://doi.org/10.3322/caac.21654.

2. Jonasch E, Gao J, Rathmell WK. Renal cell carcinoma. BMJ. 2014;349(nov10 11):g4797. https://doi.org/10.1136/bmj.g4797.

3. Comprehensive molecular characterization of clear cell renal cell carcinoma. NATURE 2013, 499(7456):43-49.

4. Jonasch E, Walker CL, Rathmell WK. Clear cell renal cell carcinoma ontogeny and mechanisms of lethality. NAT REV NEPHROL. 2021;17(4):245-61. https:// doi.org/10.1038/s41581-020-00359-2.

5. Mickley A, Kovaleva O, Kzhyshkowska J, Gratchev A. Molecular and immunologic markers of kidney cancer-potential applications in predictive, preventive and personalized medicine. EPMA J. 2015;6(1):20. https://doi. org/10.1186/s13167-015-0042-2. 
6. Nicholson JK, Lindon JC. Holmes E: 'Metabonomics': understanding the metabolic responses of living systems to pathophysiological stimuli via multivariate statistical analysis of biological NMR spectroscopic data. XENOBIOTICA. 1999;29(11):1181-9. https://doi.org/10.1080/00498259923 8047

7. Fahy E, Subramaniam S, Brown HA, Glass CK, Merrill AJ, Murphy RC, et al. A comprehensive classification system for lipids. J Lipid Res. 2005;46(5):839-61. https://doi.org/10.1194/jlr.E400004-JLR200.

8. Fahy E, Cotter D, Sud M, Subramaniam S. Lipid classification, structures and tools. Biochim Biophys Acta. 2011;1811(11):637-47. https://doi.org/10.1016/j. bbalip.2011.06.009.

9. Wang R, Li B, Lam SM, Shui G. Integration of lipidomics and metabolomics for in-depth understanding of cellular mechanism and disease progression. J GENET GENOMICS. 2020;47(2):69-83. https://doi. org/10.1016/j.jgg.2019.11.009.

10. Wenk MR. The emerging field of lipidomics. Nat Rev Drug Discov. 2005;4(7): 594-610. https://doi.org/10.1038/nrd1776.

11. Zhang L, Zhu B, Zeng Y, Shen H, Zhang J, Wang X. Clinical lipidomics in understanding of lung cancer: opportunity and challenge. Cancer Lett. 2020;470:75-83. https://doi.org/10.1016/j.canlet.2019.08.014.

12. Zhang $Q, X u H$, Liu R, Gao P, Yang X, Jin W, et al. A novel strategy for targeted Lipidomics based on LC-tandem-MS parameters prediction, quantification, and multiple statistical data mining: evaluation of Lysophosphatidylcholines as potential Cancer biomarkers. Anal Chem. 2019; 91(5):3389-96. https://doi.org/10.1021/acs.analchem.8b04715.

13. Eriksson $\mathrm{L}$, Andersson PL, Johansson E, Tysklind M. Megavariate analysis of environmental QSAR data. Part l--a basic framework founded on principal component analysis (PCA), partial least squares (PLS), and statistical molecular design (SMD). Mol Divers. 2006;10(2):169-86. https://doi.org/10.1 007/s11030-006-9024-6.

14. Thevenot EA, Roux A, Xu Y, Ezan E, Junot C. Analysis of the human adult urinary metabolome variations with age, body mass index, and gender by implementing a comprehensive workflow for univariate and OPLS statistical analyses. J Proteome Res. 2015;14(8):3322-35. https://doi.org/10.1021/acs. jproteome.5b00354.

15. Park J, Choi J, Kim DD, Lee S, Lee B, Lee Y, et al. Bioactive lipids and their derivatives in biomedical applications. Biomol Ther (Seoul). 2021;29(5):46582. https://doi.org/10.4062/biomolther.2021.107.

16. Wang C, Tong Y, Wen Y, Cai J, Guo H, Huang L, et al. Hepatocellular carcinoma-associated protein TD26 interacts and enhances sterol regulatory element-binding protein 1 activity to promote tumor cell proliferation and growth. HEPATOLOGY. 2018;68(5):1833-50. https://doi.org/10.1002/hep.30030.

17. Manzo T, Prentice BM, Anderson KG, Raman A, Schalck A, Codreanu GS, et al. Accumulation of long-chain fatty acids in the tumor microenvironment drives dysfunction in intrapancreatic CD8+ T cells. J Exp Med. 2020;217(8):217(8). https://doi.org/10.1084/jem.20191920.

18. Xiong J. Fatty acid oxidation in cell fate determination. Trends Biochem Sci. 2018:43(11):854-7. https://doi.org/10.1016/j.tibs.2018.04.006.

19. Li XX, Wang ZJ, Zheng Y, Guan YF, Yang PB, Chen X, et al. Nuclear receptor Nur77 facilitates melanoma cell survival under metabolic stress by protecting fatty acid oxidation. Mol Cell. 2018;69(3):480-92. https://doi.org/1 0.1016/j.molcel.2018.01.001

20. Park JH, Vithayathil S, Kumar S, Sung PL, Dobrolecki LE, Putluri V, et al. Fatty acid oxidation-driven Src links mitochondrial energy reprogramming and oncogenic properties in triple-negative breast Cancer. Cell Rep. 2016;14(9): 2154-65. https://doi.org/10.1016/j.celrep.2016.02.004.

21. Wakamiya T, Suzuki SO, Hamasaki H, Honda H, Mizoguchi M, Yoshimoto K, et al. Elevated expression of fatty acid synthase and nuclear localization of carnitine palmitoyltransferase $1 \mathrm{C}$ are common among human gliomas. NEUROPATHOLOGY. 2014;34(5):465-74. https://doi.org/10.1111/neup.12132.

22. Zhu J, Wu G, Song L, Cao L, Tan Z, Tang M, et al. NKX2-8 deletion-induced reprogramming of fatty acid metabolism confers chemoresistance in epithelial ovarian cancer. EBIOMEDICINE. 2019;43:238-52. https://doi.org/10.1 016/j.ebiom.2019.04.041.

23. Schlaepfer IR, Glode LM, Hitz CA, Pac CT, Boyle KE, Maroni P, et al. Inhibition of lipid oxidation increases glucose metabolism and enhances 2-Deoxy-2[(18)F]Fluoro-D-glucose uptake in prostate Cancer mouse xenografts. Mol Imaging Biol. 2015;17(4):529-38. https://doi.org/10.1007/s11307-014-0814-4.

24. Poolsri WA, Phokrai P, Suwankulanan S, Phakdeeto N, Phunsomboon P, Pekthong D, et al. Combination of mitochondrial and plasma membrane citrate transporter inhibitors inhibits De novo lipogenesis pathway and triggers apoptosis in hepatocellular carcinoma cells. Biomed Res Int. 2018; 2018:3683026-15. https://doi.org/10.1155/2018/3683026.

25. Miess H, Dankworth B, Gouw AM, Rosenfeldt M, Schmitz W, Jiang M, et al. The glutathione redox system is essential to prevent ferroptosis caused by impaired lipid metabolism in clear cell renal cell carcinoma. ONCOGENE. 2018;37(40):5435-50. https://doi.org/10.1038/s41388-018-0315-z.

26. Han S, Wei R, Zhang X, Jiang N, Fan M, Huang JH, et al. CPT1A/2-mediated FAO enhancement-a metabolic target in Radioresistant breast Cancer. Front Oncol. 2019;9:1201. https://doi.org/10.3389/fonc.2019.01201.

27. Zaugg K, Yao Y, Reilly PT, Kannan K, Kiarash R, Mason J, et al. Carnitine palmitoyltransferase 1C promotes cell survival and tumor growth under conditions of metabolic stress. Genes Dev. 2011;25(10):1041-51. https://doi. org/10.1101/gad.1987211.

28. Wang L, Li C, Song Y, Yan Z. Inhibition of carnitine palmitoyl transferase 1Ainduced fatty acid oxidation suppresses cell progression in gastric cancer. Arch Biochem Biophys. 2020;696:108664. https://doi.org/10.1016/j.abb.2020.1 08664.

29. Sadeghi RN, Karami-Tehrani F, Salami S. Targeting prostate cancer cell metabolism: impact of hexokinase and CPT-1 enzymes. Tumour Biol. 2015; 36(4):2893-905. https://doi.org/10.1007/s13277-014-2919-4.

30. Shao H, Mohamed EM, Xu GG, Waters M, Jing K, Ma Y, et al. Carnitine palmitoyltransferase $1 \mathrm{~A}$ functions to repress FoxO transcription factors to allow cell cycle progression in ovarian cancer. Oncotarget. 2016;7(4):383246. https://doi.org/10.18632/oncotarget.6757.

31. Du Q, Tan Z, Shi F, Tang M, Xie L, Zhao L, et al. PGC1alpha/CEBPB/CPT1A axis promotes radiation resistance of nasopharyngeal carcinoma through activating fatty acid oxidation. Cancer Sci. 2019;110(6):2050-62. https://doi. org/10.1111/cas.14011.

32. Gugiatti E, Tenca C, Ravera S, Fabbi M, Ghiotto F, Mazzarello AN, et al. A reversible carnitine palmitoyltransferase (CPT1) inhibitor offsets the proliferation of chronic lymphocytic leukemia cells. HAEMATOLOGICA. 2018; 103(11):e531-6. https://doi.org/10.3324/haematol.2017.175414.

33. Wettersten HI, Hakimi AA, Morin D, Bianchi C, Johnstone ME, Donohoe DR, et al. Grade-dependent metabolic reprogramming in kidney Cancer revealed by combined proteomics and metabolomics analysis. Cancer Res. 2015;75(12):2541-52. https://doi.org/10.1158/0008-5472.CAN-14-1703.

34. Huang B, Song BL, Xu C. Cholesterol metabolism in cancer: mechanisms and therapeutic opportunities. Nat Metab. 2020;2(2):132-41. https://doi. org/10.1038/s42255-020-0174-0.

35. Alfagih MA, Nelson ER, Liu W, Safi R, Jasper JS, Macias E, et al. CYP27A1 loss dysregulates cholesterol homeostasis in prostate Cancer. Cancer Res. 2017; 77(7):1662-73. https://doi.org/10.1158/0008-5472.CAN-16-2738.

36. Li J, Gu D, Lee SS, Song B, Bandyopadhyay S, Chen S, et al. Abrogating cholesterol esterification suppresses growth and metastasis of pancreatic cancer. ONCOGENE. 2016;35(50):6378-88. https://doi.org/10.1038/onc.2016.168.

37. Villa GR, Hulce JJ, Zanca C, Bi J, Ikegami S, Cahill GL, et al. An LXRcholesterol Axis creates a metabolic co-dependency for brain cancers. Cancer Cell. 2016;30(5):683-93. https://doi.org/10.1016/j.ccell.2016.09.008.

38. Park JB, Lee CS, Jang JH, Ghim J, Kim YJ, You S, et al. Phospholipase signalling networks in cancer. Nat Rev Cancer. 2012;12(11):782-92. https:// doi.org/10.1038/nrc3379.

39. Huang C, Cao Z, Ma J, Shen Y, Bu Y, Khoshaba R, et al. AKR1B10 activates diacylglycerol (DAG) second messenger in breast cancer cells. Mol Carcinog. 2018;57(10):1300-10. https://doi.org/10.1002/mc.22844.

40. Jia W, Xie G. Probiotics, bile acids and gastrointestinal carcinogenesis. Nat Rev Gastroenterol Hepatol. 2018;15(4):205. https://doi.org/10.1038/nrgastro.2018.24.

41. Ma C, Han M, Heinrich B, Fu Q, Zhang Q, Sandhu M, et al. Gut microbiomemediated bile acid metabolism regulates liver cancer via NKT cells. SCIENCE. 2018;360(6391):360(6391). https://doi.org/10.1126/science.aan5931.

42. Hang S, Paik D, Yao L, Kim E, Trinath J, Lu J, et al. Bile acid metabolites control TH17 and Treg cell differentiation. NATURE. 2019;576(7785):143-8. https://doi.org/10.1038/s41586-019-1785-z.

43. Song $X$, Sun $X$, Oh SF, Wu M, Zhang Y, Zheng W, et al. Microbial bile acid metabolites modulate gut RORgamma(+) regulatory $T$ cell homeostasis. NATURE. 2020;577(7790):410-5. https://doi.org/10.1038/s41586-019-1865-0.

44. Mickley A, Kovaleva O, Kzhyshkowska J, Gratchev A. Molecular and immunologic markers of kidney cancer-potential applications in predictive, preventive and personalized medicine. EPMA J. 2015;6(1):20. https://doi. org/10.1186/s13167-015-0042-2

45. Du W, Zhang L, Brett-Morris A, Aguila B, Kerner J, Hoppel CL, et al. HIF drives lipid deposition and cancer in $\mathrm{CCRCC}$ via repression of fatty acid 
metabolism. Nat Commun. 2017;8(1):1769. https://doi.org/10.1038/s41467-01 7-01965-8.

46. Kim J, Thompson B, Han S, Lotan Y, McDonald JG, Ye J. Uptake of HDLcholesterol contributes to lipid accumulation in clear cell renal cell carcinoma. Biochim Biophys Acta Mol Cell Biol Lipids. 2019;1864(12):158525. https://doi.org/10.1016/j.bbalip.2019.158525.

47. Bombelli S, Torsello B, De Marco S, Lucarelli G, Cifola I, Grasselli C, et al. 36$\mathrm{kDa}$ Annexin A3 isoform negatively modulates lipid storage in clear cell renal cell carcinoma cells. Am J Pathol. 2020;190(11):2317-26. https://doi. org/10.1016/j.ajpath.2020.08.008.

48. Tan SK, Welford SM. Lipid in renal carcinoma: queen bee to target? Trends Cancer. 2020;6(6):448-50. https://doi.org/10.1016/j.trecan.2020.02.017.

49. Sanchez DJ, Simon MC. Genetic and metabolic hallmarks of clear cell renal cell carcinoma. Biochim Biophys Acta Rev Cancer. 2018;1870(1):23-31. https://doi.org/10.1016/j.bbcan.2018.06.003.

50. Xu D, Wang Z, Xia Y, Shao F, Xia W, Wei Y, et al. The gluconeogenic enzyme PCK1 phosphorylates INSIG1/2 for lipogenesis. NATURE. 2020;580(7804):5305. https://doi.org/10.1038/s41586-020-2183-2.

51. Hui S, Ghergurovich JM, Morscher RJ, Jang C, Teng X, Lu W, et al. Le Zhan, Yanxiang GJ et al: glucose feeds the TCA cycle via circulating lactate. NATU RE. 2017;551 (7678):115-8. https://doi.org/10.1038/nature24057.

52. Lucarelli G, Loizzo D, Franzin R, Battaglia S, Ferro M, Cantiello F, et al. Metabolomic insights into pathophysiological mechanisms and biomarker discovery in clear cell renal cell carcinoma. Expert Rev Mol Diagn. 2019; 19(5):397-407. https://doi.org/10.1080/14737159.2019.1607729.

53. Bianchi C, Meregalli C, Bombelli S, Di Stefano V, Salerno F, Torsello B, et al. The glucose and lipid metabolism reprogramming is grade-dependent in clear cell renal cell carcinoma primary cultures and is targetable to modulate cell viability and proliferation. Oncotarget. 2017;8(69):113502-15. https://doi.org/10.18632/oncotarget.23056.

54. Van Daal JH, De Kok YJ, Jenks BG, Wendelaar BS, Van Abeelen JH. A genotype-dependent hippocampal dynorphinergic mechanism controls mouse exploration. Pharmacol Biochem Behav. 1987;28(4):465-8. https://doi. org/10.1016/0091-3057(87)90507-7.

55. Ragone R, Sallustio F, Piccinonna S, Rutigliano M, Vanessa G, Palazzo S, et al. Renal Cell Carcinoma: A Study through NMR-Based Metabolomics Combined with Transcriptomics. Diseases. 2016;4(1):4(1). https://doi.org/1 0.3390/diseases4010007.

56. Lucarelli G, Rutigliano M, Sallustio F, Ribatti D, Giglio A, Lepore SM, et al. Integrated multi-omics characterization reveals a distinctive metabolic signature and the role of NDUFA4L2 in promoting angiogenesis, chemoresistance, and mitochondrial dysfunction in clear cell renal cell carcinoma. Aging (Albany NY). 2018;10(12):3957-85. https://doi.org/10.1 8632/aging. 101685.

57. Lucarelli G, Ferro M, Loizzo D, Bianchi C, Terracciano D, Cantiello F, et al. Integration of Lipidomics and Transcriptomics Reveals Reprogramming of the Lipid Metabolism and Composition in Clear Cell Renal Cell Carcinoma. Metabolites. 2020;10(12):10(12). https://doi.org/10.3390/metabo10120509.

\section{Publisher's Note}

Springer Nature remains neutral with regard to jurisdictional claims in published maps and institutional affiliations.

Ready to submit your research? Choose BMC and benefit from:
- fast, convenient online submission
- thorough peer review by experienced researchers in your field
- rapid publication on acceptance
- support for research data, including large and complex data types
- gold Open Access which fosters wider collaboration and increased citations
- maximum visibility for your research: over 100M website views per year
At BMC, research is always in progress.
Learn more biomedcentral.com/submissions

